\title{
Fostering Technology Use Among Second-Wave Foreign Language Faculty
}

\author{
Edwina Spodark \\ Hollins University
}

The study of new classroom technologies dedicated to foreign language teaching has been extensive and ongoing. As Liontas observes: "Unlike any other time in the era of instructional technology, the last two decades of the twentieth century saw an explosive growth of articles, monographs, books, and conferences on CALL and multimedia applications to second language learning" (2001). Given this evidence of a strong interest in computer-enhanced pedagogy among foreign language professionals, it comes as no surprise that a large number of language teaching faculty have worked diligently to transform their classes into computer-enhanced language learning experiences. These professors fall into the category of what are known as first-wave or entrepreneurial faculty, that is faculty "who seek out the resources and the expertise to implement their own personal commitment to incorporating technology into their own learning environments" (Educause 2000). Their pedagogical vision and goals for their students drive their decisions to incorporate new technologies into their classrooms.

A recentNational Learning Infrastructure Initiative white paper confirms this rationale among first-wave entrepreneurs: "Almost to a person, the central reason given for undertaking these innovations was that it 'was the right thing to do' or 'the students deserved to have the quality of their education improved'" (2000). Yet, as this same white paper clarifies, "these educators do not represent the mainstream but, rather, are at the vanguard." The majority of foreign language faculty today falls into a second wave of educational professionals who are reluctant to integrate computers into their daily classroom practices. As the following statistics by Larry Cuban attest, a large percentage of second-wave faculty do not incorporate technology regularly into their classes but the numbers also 
suggest that this may not be due to technophobia, as is often the automatic assumption:

Out of every 10 teachers in this country, fewer than two are serious users of computers and other information technologies in their classrooms (several times a week); three to four are occasional users (about once a month); and the rest - four to five teachers out of every 10 -never use the machines atall....Of those same 10 American teachers, about seven have computers at home and use them to prepare lessons, communicate with colleagues and friends, search the Internet, and conductpersonal business. In short, most teachers use computers at home more than at school (1999).

In fact, although a "full 87 percent of faculty agree that 'student use of computers enhances their learning,' [t]wo-thirds of college and university faculty (67 percent) report that 'keeping up with information technology' has proved to be stressful for them... and [only] 22 percent use computers in undergraduate course instruction" (Sax 2000).

Faced with this gap between the high faculty support (87\%) for the proposition that computers enhance student learning and the relatively low percentage of faculty (22\%) who actually use computers in undergraduate course instruction, the question arises: whatstands in the way of faculty incorporating technology into their classrooms? "Some factors that prevent faculty from pursuing technological innovations are: fear of change, fear of time involved, fear of appearing incompetent, fear of technobabble, fear of failure, not knowing where to start, fear of making bad choices, fear of typing, and fear of reprisals and rejection..." (Hartman, Dzuiban and Moskal 2000). Add to these reasons the resentment associated with the perception that technology is often pushed upon faculty by administrators who are swayed by vendors' insistence that without the latest advancements their institutions will be left behind. Decisions about hardware and software are often made at an administrative level without regard to pedagogical necessity or implications. As Andrew Feenberg observes: "What was once a daring faculty innovation [has] come to be perceived as a big-business takeover of the university" (1999). "Best Practices in Faculty Engagement and Support," a white paper for a National Learning Infrastructure Initiative focus session at the 2000 Educause meeting, suggests there are three more "possible sources of hesitancy... 
- Fear of the Unknown-Faculty, especially older faculty, are quite used to being in control of their subjectmatter, and in the way they present it. Adopting new technological forms of presentation necessarily demands a learning curve, the dimensions and length of which they are unsure.

- 'If it Ain't Broke...' - We have encountered many faculty who excel in 'face-to-face' forms of learning but whoresist the new technologies. They offer at least two arguments in support of their attitude. First, if they are doing a superior job already, why change? Thesecond reason is more pragmatic: They know they are good educators now, but there is no assurance that this success will translate across different forms of presentation.

\section{With all the reasons cited above to stop them from creating their own computer- enhanced language learning classrooms, there is one overriding factor that should compel faculty to make the effort: students will benefit from the classroom use of the new technologies.}

- 'We're All Alone in this Together' - Unlike the 'entrepreneurs,' potential second-wave faculty will demand more 'user-friendly' levels of institutional support. The greater the apparent effort to adapt, the more likely the first two reasons above all come to dominate the faculty's thinking."

With all the reasons cited above tostop them from creating their own computer-enhanced language learning classrooms, there is one overriding factor that should compel faculty to make the effort: students will benefit from the classroom use of the new technologies.

Among the more daunting reasons that many second-wave foreignlanguage faculty cite for their reluctance to use technology in the classroom is that they don't know how or where to start. The answer to this dilemma is relatively transparent:start with what you know and enhance something that already seems to work. Start with a lesson that has worked well in the past but that you intuitively feel needssomethingmore. A lesson that's working well but that you'resure could be improved upon. This provides the comfort zone needed to make the transition to a computer-enhanced classroom by working with familiar material and goals and reduces the amount of extra time that will be required to make the lesson a success. This solution has the added advantage of being accompanied by its own back-up plan in case of machine failure. This reduces the fear of what to do if the computer doesn't work - there's a built-in "plan B" 
- just go back to the old approach and try the technology again later. This may not present a completely satisfying solution but it will eliminate a lot of the anxiety in dealing with technology in the classroom perhaps enough so that teachers can witness the benefits to students first-hand.

By way of illustration, I offer an analysis of the changes I have made to the first day of class in an Intermediate French language course that I teach at Hollins University. For years, I used the following lesson very successfully to reintroduce students to hearing, speaking and writing French after a summer hiatus in theirstudy of thelanguage. Ibegan the class with an introduction to the coursesyllabus, books, small-group conversationsessions, homework assignments and deadlines and other course management items. After initially asking students "getting to know you" sorts of questions in French and having them ask each other for personal information using the target language (Quel âge as-tu? D'où viens-tu? Qu'est-ce que tuétudies, Où habitestu?, etc.), I moved on to a writing activity. I handed out blank index cards to which I had affixed colorful "stamps" (usually Easter seals or other decorative stamps that I had found) in the upper right-hand corner. Thestudents were to write a postcard and introduce themselves to the teacher. Before they began, however, the class reviewed, in French, the various components of a postcard-l'expéditeur I'expéditrice, le destinataire, l'adresse, le timbre, la date, la salutation, etc. - by drawing a postcard on the blackboard and filling in the relevant information that they would need. They then wrote an 8-10 sentence postcard to introduce themselves to me. Next, using a large yellow replica of a French post box, each student came up and "mailed" her postcard by putting it through the appropriate slot ("Autres Destinations" and not the one marked "Paris Seulement") on the cardboard mailbox.

This activity allowed the students to speak only French in the classroom and to use vocabulary and structures that they had learned at the elementary level during the question/answer portion of the class. It also framed the writing activity in a familiar, real-world application so that all discussion about it could take place in the target language. The "authentic" French mailbox brought an importantelement of daily French cultural life into the classroom. This lesson provided students with a comfortable, successful, positive reintroduction to their language study and appealed to all three of the major categories of student preferred learning styles: they spoke and listened to each other in the question/answer portion of the class (audio), they saw a 


\section{Could computer} enhancement of the lesson give me the extension into creative use of the language that / was looking for? visual representation of the various segments of the postcardwriting activity (visual), and they wrote as well as physically "mailed" their postcards (haptic). All in all, it was a wellrounded lesson that accomplished my pedagogical goals for the first day of class. And yet, I wasn't completely satisfied with it. Even though this introductory lesson had worked very well for many years, falling solidly in the "if it ain't broke, don't fix it" category, I knew, upon honest introspection, that it could be improved upon.

Although thestudents feltcomfortableworking with the familiar material and they had little trouble speaking up, I had never been fully satisfied with their lack of creative use of the target language on this first day of class. In my original course activities, students simply reviewed elementary vocabulary and structures. Could computer enhancement of the lessongive me the extension into creative use of the language that I was looking for? I found Meskill's advice encouraging: "What this period of experimentation with computers in teaching and learning does indicate is that the power of the medium lies in how well it gets used and integrated into the daily classroom scheme so that active engagement in acquisition-oriented work takes place; that is, through integrated, sociocollaborative processes that value active thinking and action with language being both tool and target of the activity" (1999). I needed to devise a way to encourage students to interact with and in the target language and engage their critical thinking skills at the same time.

Asecond pedagogical goal that propelled me towards computer enhancement of this lesson was my desire to include more cultural material on this first day. I wanted my students to understand that elements of comparative cultural analysis would play a large contextual role throughout our review of the language itself. However, Furstenberg reminds us: "One common assumption in the field of foreign languageinstruction is that when we teach language, we also teach culture.... Culture is seldom integrated into the teaching of the language and even more rarely comes to the forefront" (2000). I wanted to takesteps to ensure that my students saw culture as one of the essential elements of the course and that they would intuitively understand "that language learning is facilitated by use of the target language in content-rich and purposeful ways while an active awareness of the forms and functions of language is maintained" (Meskill 1999). 
Given these additional objectives, Idecided to keep a shortened version of the initial basic question/answer portion of the lesson as anon-threatening warm up activity and settled on the post card writing as the area that could be expanded and enriched via the use of technology to address my pedagogical concerns and goals. I realized that the basic elements for success were already there; all Ineeded to do was decide how I wanted to enhance that part of the lesson.

To start my reconfiguration of the lesson, I transferred the outlining of the familiar post card writing activity from the chalkboard to Powerpointslides. In order to review the sections in French, each part of the postcard was identified on the slide just as it had been at the board. To add a more culturally authentic look to the slide, I went to the Web site of the French post office (http://wwww. laposte.fr) to find a picture of an authentic French stamp. There I discovered the 1999 Marianne series of stamps. Now, I could have bought the Mariannestamps via the Internet and had them to pass around in class thereby effectively bypassing the need for technology in my classroom. However, I chose instead to use an image of the stamp from the post office Web site on a PowerPoint slide to help focus my students' attention forward on the class discussion and not on a small object held in their hands. As I inserted a replica of the stamp onto the postcard Ihaddrawn on theslide, everythingsuddenly clicked. The symbol of Marianne would serve as the foundation formy culturelesson on this first day. I would employ technology to create a network of meaning that would combine language skills and cultural connotations around the symbol of Marianne. It was a perfect choice given the breadth of associations that could be made. And with Hollins University being a university for women, the students would undoubtedly have a good deal to say about a woman as one of the cultural symbol of a nation.

After reviewing the varioussections of the postcard, I wentback to the Marianne stamp. I asked students to brainstorm about who this woman was on the stamp and why they thought she would have been chosen to appear there. When I revealed that the woman was Marianne, a symbol of the country of France itself, I asked students to tell me why she might represent France. I also asked them to tell me what they thought about a woman as the cultural icon of France and how that might compare to the cultural symbols of the United States. These kinds of thoughtful questions stimulated students' curiosity and motivated them to use the French language skills that they had to express original ideas and opinions. This sort of active, creative participation 
was a far cry from simply answering questions about their age, family situation and preferences. As Meskill observes: "The optimal role for language learners is active. It is through active participation in thinking and using the target language that the opportunity for language acquisition is maximized. Examination of learning contexts where computers are used to enable and supportstudent-centered tasks reveals that features of task and medium in consort contribute to optimal, active student engagement" (1999). This activity fostered just the type of energy and creativity I was seeking to include in my first-day lesson.

These intriguing opening questions inspired the class to explore more fully the cultural significance of Marianne. Given the initial activity theme of postcard writing, Istarted with the most obvious use of this national symbol-stamps. For this exchange, I used two other examples of past stamp series depicting Marianne issued by the French post office. These stamps had long since been out of print but I was able to find images of them on the Web site of the French Prime Minister's Office (http:// www.premier-ministre.gouv.fr/fr) and incorporate them into the discussion. Thus, it was only with the help of the Internet that we were able to examine various incarnations of Marianne on thestamps of France. As a group, the students considered such questions as: How are the illustrations different? What do they all have in common? How do they retain their meaning as symbols? Why would Marianne be such a popular symbol to use? What femaleimages appear on U.S.stamps? How do they compare to the various Marianneseries? Even the students with the weakestFrenchskills wereable to makecontributions to this discussion thusadding to the debate as well as to theirconfidence when using the target language.

The next logical phase of our exploration was to discuss other appearances of Marianne in French culture. In contrast to the prosaic use of Marianne's image on the stamp, the class took a look at the most famous representation of this French cultural icon, taken from the Louvre Web site (http://wwww.louore.fr), Delacroix's La Liberté guidant le peuple. Although I could have taken the time and found a copy of this painting in abook in our library, Ichose instead to use the graphicimage from the Louvre Web site for two reasons. First, I wanted to indicate tacitly to my students a way to delve further into the prodigious wealth of French art housed at that Web site, so I made sure that the Web address was available on our class Blackboard site and encouraged students to explore it on their own. I am always 
eager to foster or support any and all interest in aspects of French culture amongstudents. Butmore importantly, Idecided to use the image from the Louvre Web site on a PowerPoint slide, in order not to interrupt the flow of the discussion. To this point students were completely focused on the discussion stimulated by the visuals that were before them. They paid very little attention to my casually hitting the space bar on the computer to advance to the next slide, and I didn't want to break the flow of the discussion by suddenly contrasting the technology I was using with another medium. Therefore, while admiring this fascinating work of art, we reviewed briefly in the targetlanguage what the class knew about the French revolution, supplemented by information provided by the professor. This naturally occurring mini-lecture was a good test of students' aural comprehension skills on this first class day and provided students with a short introduction to this important national event. We also speculated on why this particular painting served as such an inspirational depiction of that chapter in French history.

After the discussion of the Marianne as symbol of the revolution and her place in the formal art of the nation, I wanted to remind the students that she nevertheless played an important role in the everyday life of the French people as well. Thus the class embarked on a review of Marianne as she appeared in more commonplace venues. Ibegan with a commercial advertisement. An obvious takeoff on the Delacroix painting comes from the RoquefortLovers Website (http://wwww.roquefortlovers.com). This Web site allowed us the opportunity to learn about the very timely debate regarding the fairness of U.S. tariffs beingimposed on French cheeses and other delicacies from France and, at the same time, to examine why Marianne would appear in this campaign and what her appearance there meant. Available only through the Roquefort Lovers Web site, this illustration of Marianne graphically impressed upon thestudents the enduring meaning of this cultural icon and brought home to them the power the use of her likeness continues to have even to this day.

The next area for consideration was the ubiquitous article of money. By discussing the use of Marianne on French currency, we returned to the roots of the French symbol's meaning to the nation. She not only appeared on the French franc ( $h$ ttp:// www.monnaiedeparis.com) but she will also be the subject of the French side of the new Euro coin (http://www.finances.gouv.frl euro). Thus, she represents France's past economic stability as well as her future. Insofar as there were no Euro coins available, 
the Internet was the only way to demonstrate to thestudents the abiding respect and attachment that the French have for this particular symbol of their nation. The exchanges regarding Marianne's monetary representations spurred students to ask questions about the new European Union and surmise what it would mean to France and the United States. This contemplation of French coins also led the class to consider the American use of symbols on its currency. What symbols most often appear on American coins? How do they illustrate a possible differing world view from the French? As Furstenberg reminds us: "[there is] one powerful feature of interactive technologies: their capacity to bring forward and connect different types of materials. The sheer process of juxtaposition allows variations that would otherwise stay buried and undiscovered to emerge and be revealed" (2000). This discussion allowed students to open up and examine their own personal assumptions and ways of seeing the world.

Finally, the students summarized how Marianne acted as a symbol of France's past, present, and future. They speculated on why she was such a powerful symbol of the nation. They gave arguments abouthow itshould be that a woman served as thesymbol of France. All of this took place in the targetlanguage on the first day of class in an intermediate level French course. "The classroom thus becomes the place where discoveries, insights, ideas, are brought together, confronted, and discussed. It is the place wherestudents start developing out of that mosaic of information - with the help of the teacher [and] their own classmates...-their own Web of interpretations and an overall, global understanding of the other culture: how it works, what it is based on, and whyit functions the way itdoes" (Furstenberg 2000). This technology-led activity encouraged my students to view the symbol of Marianne as a French person might and to try to understand its use from another point of view. It served as a powerful introduction to a comparative approach of cultural study that would continue throughout the course.

After the examination of the role of Marianne as symbol in French culture, the class returned to the post card writing activity and each student wrote her card to the teacher and "mailed" it by putting it in the yellow French mailbox replica as previously described. But we did not end this session there. We extended our secondary theme of stamps, mailboxes and post card writing one last time by visiting the link for the Wall of Peace on the Internet site for the French Postal Service ( $h t t p: /$ /www.laposte.fr). Here we worked as one group to craft an 
Using technology [...] makes it easier to keep all interaction in the target language. It speaks to the various audio, visual and haptic learning styles of students. It allows for constructivist learning where students create their own learning experience. It opens up networks of meaning for students by readily combining materials thatmight otherwise be difficultor impossible to acquire. individual message to be included on the video monitors in Paris that made up this symbolic call for peace around the world. As the class worked together as a group, the cooperation and common purpose of using the target language to express their own personal ideas helped students to bond with each other and recognize their shared, common goals of learning the language in order to use it in real life situations. A positive consequence resulting from this last activity was that it created a synergy which lasted the rest of the term. "Thanks to this approach and the Web, culture is no longer reduced to a series of facts about the other country but built on a dynamic process that involves interactions with multiple materials - raw or mediated - and multiple partners - learners, teachers, other students, and experts. Culture is no longer an abstract notion but becomes both a personal and a shared experience - shared not just with other students in the class, but with other people on the other side of the World Wide Web line" (Furstenberg 2000). This remarkable development would not have been possible without the use of technology in the classroom.

The exampledescribed above underscores notonly the feasibility of incorporating technology into foreign language lessons; it also demonstrates the advantages of doingso. Using technology responds to the goals of the second language classroom in any number of ways. It makes it easier to keep all interaction in the target language. It speaks to the various audio, visual and haptic learning styles of students. It allows for constructivist learning where students create their own learning experience. It opens up networks of meaning for students by readily combining materials that might otherwise be difficult or impossible to acquire. It affords students the opportunity to do things that they could not do if it weren't for the Internet and the World Wide Web. Yet McDonough's caveat is important: "...[I]n order to use computer technology to the greatest advantage, teachers must consider computers as tools to help them achieve their instructional goals. In other words, using computer technology in the classroom is not guaranteed to miraculously enhance learning all by itself. Wise, purposeful planning on the part of the teacher, as well as integration into the curriculum must accompany its use" (2001). Although some faculty fear a certain loss of control when the computerenhanced learning environment becomes student-centered, they must remember that their pedagogical goals structure that environment. They are the heavenly architects of the learning experience, infusing the classroom with direction, purpose and meaning, and technology can be one of their most powerful 
resources.

Second-wave foreign language faculty must accept that they can be successful in incorporating technology into their classrooms as long as they rely on their pedagogical goals to guide them. "When good pedagogy drives technology, electronic media become tools thatstretch the boundaries of teaching and learning..." (Friedheim and Jaffe 1999). Faculty may need to start with small steps that take them through familiar territory and give them confidence. They mightstart by reconfiguring a lesson or a part of a lesson that has been useful to them in the past but that they believe would benefit from enhancement. A recent study by the American Association for History and Computing "suggests that the mosteffective use of instructional technology is being made in small-class settings, where technology is being adopted not just to promote efficiency or ameliorate crowded classrooms, but to be integrated into classes that also provide face-to-face interaction" (Trinkle 1999). Foreign language classrooms are ideally situated to take advantage of this implication. Restructuring a lesson to capitalize on the technology available will take time and energy, but the undertaking will be worth the effort. One major reason is that students respond very favorably to the incorporation of technology. "Segmented modelsshow media-enhanced courses having higher success and lower withdrawal rates than traditional or fully on-line courses. When media-enhanced and fully on-line classes are matched with traditional sections, media-enhanced versions are superior in having greater numbers of students succeeding with an A, B, or C grade, and fewer withdrawals" (Hartman, Dziuban, and Moskal 2000). Once second-wave faculty have experienced for themselves the kinds of synergisticlearning that technology engenders among students, they often become someits moststeadfast proponents. As Hartman, Dziuban and Moskal found: "The highest satisfaction levels [among faculty]... were found in the mediaenhanced courses" (2000). Brown succinctly summarizes this faculty conversion: "It is noaccident that virtually all professors whohave added technological enhancements to their repertoire of teaching tools are persevering. Studentswin" (2000). It is this combination of value to students and the realization of faculty pedagogical objectives for them that makeintegrating technology in service to foreign language learning an essential goal for all practicing classroom teachers. * 


\section{Bibliography}

Brown, D. G. 2000. Assessment of technology's impact on learning:an overview. Intereactioe Learning: Vignettes from America's Most Wired Campus, ed.D.G. Brown. Boston, MA: Anker Publishing Company.

Cuban, L. 1999. The technology puzzle: why is greater accessnot translating into better classroom use? Education Week 18 (43): $68,47$.

Educause. 2000. Best practices in faculty engagement and support: raft prepared for a National Learning Infrastructure Initiative focussession Feb. 14,2000. Seattle, WA:http://wrow.educause.edu/nlii/meetings/seattle 2000/[cited 5 February 2000].

Feenberg, A. 1999. No frills in the virtual classroom. Academe: Bulletin of the American Association of University Professors . September-October:26-31.

Friedheim, W. and D.Jaffe. 1999. From the electronic classroom. Academe: Bulletin of the American Association of University Professors.September-October: 56-60.

Furstenberg, G. and S. Waryn. 2000. A cross-cultural, Webbased approach to developing students' understanding of a foreign culture. Interactive Learning: Vignettes from America's Most Wired Campus. ed. D. G. Brown, 246-249. Boston, MA: Anker Publishing Company.

Hartman,J.,C.Dziuban and P.Moskal. 2000. Faculty satisfaction in ALNs: a dependent or independent variable? On-line Education: Learning Effectiveness and Faculty Satisfaction, Proceedings of the 1999 Sloan Summer Workshop on Asynchronous Leaming Networks, ed. J. Bourne, 151-172. Nashville, Tennessee: Center for Asynchronous Learning Networksat Vanderbilt University.

Liontas, J.2001. Reading and multimedia annotations: beyond bells and whistles, hot links and pop-up windows. IALL Journal of Language Learning Technologies 33 (1): 53-78.

McDonough,S.K. 2001. Way beyond drill and practice: foreign language lab activities insupport of constructivistlearning. International Journal of Instructional Media 28 (1): 75-80.

Meskill, C. 1999. Computers as tools for sociocollaborative 
language learning. Computer Assisted Language Leaming: Media, Design and Applications, ed. K. Cameron, 141-162. Lisse, The Netherlands: Swets \& Zeitlinger Publishers.

Sax, L. 2000. An overview of the 1998-99 faculty norms. Graduate School of Education and Information Studies at UCLA: www.gseis.ucla.edu/heri/Faculty_Ooeroiew.html [cited 4 January 2000].

Trinkle, D. A. 1999. Distance education a means to an end, no more, noless. The Chronicle of Higher Education 6, August: A60.

Edwina Spodark, Ph.D., is Associate Professor of French at Hollins University. Her recent publications include "A French Lesson for the Multi-media Classroom" and "Integrating Online Techniques into Undergraduate French Language Instruction" in the October 2000 and May 2001 issues respectively of the French Review. Her essay "The Changing Role of the Teacher: $A$ Technology-Enhanced, StudentCentered Lesson on French Fashion" appears in Foreign Language Annals, Jan/Feb 2001. 
Spodark 